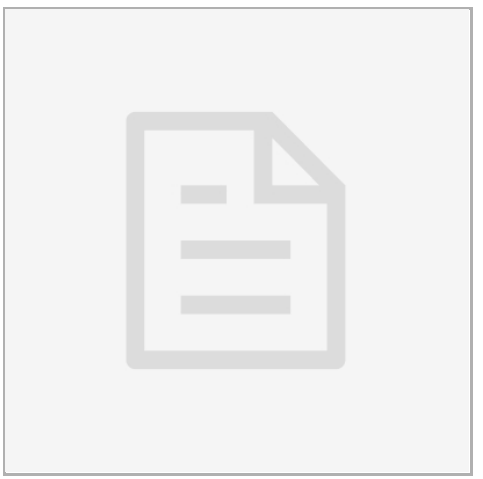

VERSION 1

DEC 06, 2019

\section{open 2 access}

\section{DOI:}

dx.doi.org/10.17504/protocol s.io.97jh9kn

Protocol Citation: Diep R Ganguly 2019. Dyeterminator DNA sequencing. protocols.io

https://dx.doi.org/10.17504/p rotocols.io.97jh9kn

License: This is an open access protocol distributed under the terms of the Creative Commons Attribution License, which permits unrestricted use, distribution, and reproduction in any medium, provided the original author and source are credited

Protocol status: Working We use this protocol and it's working

Created: Dec 06, 2019

Last Modified: Dec 06, 2019

PROTOCOL integer ID: 30667

\section{(3) Dye-terminator DNA sequencing V.1}

Diep R Ganguly ${ }^{1}$

${ }^{1}$ University of Pennsylvania

Diep R Ganguly

University of Pennsylvania, The Australian National Universi...

\section{ABSTRACT}

This protocol (based on the BigDye ${ }^{\circledR}$ Terminator v3.1 Cycle Sequencing Kit) is for performing terminator cycling sequencing reactions for Sanger sequencing of amplified PCR products or plasmid DNA on the 3130X genetic analyser (Applied Biosystems).

\section{ATTACHMENTS}

BigDye Terminator v3.1.pdf

\section{MATERIALS}

\section{MATERIALS}

88 Antarctic Phosphatase - 1,000 units New England Biolabs Catalog \#M0289S

8896 well PCR Plate Non-skirted Phenix Research Catalog \#MPS499

Nuclease-free water (e.g. MilliQ or HPLC grade water) Contributed by 8 users

88 primers Contributed by users

88 EDTA Contributed by users

10 mM dNTPs Life Technologies Catalog \#10297-

88018

Ethanol Merck Millipore Catalog

\#100983

8. BigDye $^{\text {TM }}$ Terminator v3.1 Cycle Sequencing Kit Thermo Fisher Catalog \#4337454

Exonuclease I (E. coli) NEB Catalog

\#M0293S

$88 \mathrm{Hi}^{-\mathrm{Di}^{\mathrm{TM}}}$ Formamide Thermo Fisher Scientific Catalog \#4311320 
Keywords: Sanger

sequencing, Dye-terminator sequencing

\section{BEFORE START INSTRUCTIONS}

Optimize PCR cycling (if sequencing amplified PCR products) to ensure your reaction produces a single product. Perform gel excision or PCR clean-up with the potential inclusion of incubating with Antarctic phosphatase and Exonuclease 1 to dephosporylate and degrade unincorporated dNTPs in PCR reactions to prepare templates for DNA sequencing.

\section{Terminator cycling reaction}

1 Perform sequencing reaction with BigDye Terminator cycling kit and either forward or reverse primers, or both.

\begin{tabular}{|c|c|}
\hline $\begin{array}{l}\text { Comp } \\
\text { onent }\end{array}$ & $\begin{array}{l}\text { Volu } \\
\text { me } \\
(\mu l)\end{array}$ \\
\hline $\begin{array}{l}2.5 X \\
\text { Reacti } \\
\text { on } \\
\text { Ready } \\
\text { Mix }\end{array}$ & 4 \\
\hline $\begin{array}{l}5 X \\
\text { BigDy } \\
\text { e } \\
\text { Seque } \\
\text { ncing } \\
\text { buffer }\end{array}$ & 2 \\
\hline $\begin{array}{l}20 \mu \mathrm{M} \\
\text { F/R } \\
\text { Prime } \\
r\end{array}$ & 1 \\
\hline $\begin{array}{l}\text { Templ } \\
\text { ate } \\
\text { (plas } \\
\text { mid } \\
\text { or } \\
\text { clean } \\
\text { ed } \\
\text { PCR } \\
\text { produ } \\
\text { ct) }\end{array}$ & $\begin{array}{l}150- \\
300 \\
\text { ng } \\
\text { dsDN } \\
\text { A or } \\
\text { appro } \\
\text { x } \\
10 n g \\
\text { PCR } \\
\text { produ } \\
\text { ct } \\
\text { (see } \\
\text { BigDy } \\
\text { e } \\
\text { manu } \\
\text { al) } \\
\end{array}$ \\
\hline $\begin{array}{l}\text { Nucle } \\
\text { ase- } \\
\text { free } \\
\text { water }\end{array}$ & $\begin{array}{l}\text { to } 20 \\
\mu \mathrm{l}\end{array}$ \\
\hline
\end{tabular}

BigDye Terminator Cycling reaction 
2 Set the following protocol and allow thermal cycler to reach $96^{\circ} \mathrm{C}$ :

1. $1 \mathrm{~min}$ at $96^{\circ} \mathrm{C}$

2. 30 cycles consisting of: $96^{\circ} \mathrm{C}$ for 10 seconds, $50{ }^{\circ} \mathrm{C}$ for 5 seconds, and $60^{\circ} \mathrm{C}$ for $4 \mathrm{~min}$.

3. Hold at $10^{\circ} \mathrm{C}$.

\section{Purify products}

3 To the PCR reaction, add $60 \mu \mathrm{L} 100 \%$ ethanol and $5 \mu \mathrm{l} 125 \mathrm{mM}$ EDTA.

$4 \quad$ Incubate at room temperature for 15 minutes.

$5 \quad$ Centrifuge at $4{ }^{\circ} \mathrm{C}$ at max speed for 10 minutes.

6 Remove as much supernatant as possible, then allow to air-dry in the dark for 10-15 minutes.

\section{Resuspend products and submit for sequencing}

7 Resuspend the pellet (likely transparent) in $20 \mu \mathrm{L} \mathrm{HiDi} \mathrm{Formamide} \mathrm{(add} 20 \mu \mathrm{L}$ to any empty wells). Spin down briefly.

8 Submit for sequencing on 3130X genetic analyser (Applied Biosystems). 